\title{
Cognitive-Functional Interaction in Patients with Vascular Dementia
}

\section{Edith Labos ${ }^{1 *}$, Karina Zabala ${ }^{2}$, Miriam Del Rio ${ }^{2}$, Sofía Trojanowski ${ }^{2}$, Alejandro Renato and Osvaldo Fustinoni ${ }^{2}$}

\author{
${ }^{1}$ Instituto de Investigaciones Cardiologicas Profesor Dr. Alberto C. Taquini, Universidad de Buenos Aires, \\ Argentina
}

${ }^{2}$ Facultad de Medicina. Universidad de Buenos Aires, Buenos Aires, Argentina

*Corresponding author: Edith Labos, Instituto de Investigaciones Cardiologicas Profesor Dr. Alberto C. Taquini Marcelo Torcuato de Alvear 2270, C1122AAJ, Buenos Aires, Argentina

\begin{abstract}
Background: There is a close interaction between cognitive and functional performance in the normal brain. It increases in cases of brain disease, where a worse initial cognitive performance is associated with subsequent functional decline.
\end{abstract}

Objective: To describe the cognitive and functional performance profile and their interaction in a population of patients with Vascular Dementia (VD).

Methods: We studied 79 patients (Group 1, G1) with VD and 80 healthy subjects without brain disease (Group 2, G2). The following tests were administered to all the study population: ADAS Cog., Trail Making Test (TMT), Mini Mental State Examination (MMSE), Basic and instrumental activities of daily living (ADL, IADL), Disability Assessment for Dementia (DAD), and Gottfries-Brane-Steen Scale (GBS). Scores were statistically evaluated usingthe ANOVA Test, Spearman's correlation matrix and Principal Component Analysis (PCA).

Results: The average age of $\mathrm{G} 1$ was $72.6+7.1$ and their literacy level was $8.05+4.76$ years. The cognitive profile showed a significant global decline in the MMSE $(19.9+$ 3.77 points) and in the ADAS Cog $(29.2+8.80$ points $)$. In this group, the cognitive functions most compromised were Memory, Orientation and Recognition and, to a lesser degree, Attention, Language and Praxis. The functional profile showed the greatest impairment in IADL. The PCA showed a correlation of ADAS with TMT and Katz Index, and of MMSE and DAD.

Conclusions: The results highlight the interaction between complex functional performance and cognition, suggesting an impact of cognitive impairments linked to executive function on functional performance, of potential therapeutic significance.

\section{Keywords}

Cognition, Vascular dementia, Cognitive Assessment, Functional performance, Executive Function

\section{Introduction}

Vascular Dementia (VD) is the most frequent type of dementia after dementia of the Alzheimer's type (DAT). Its prevalence increases exponentially with age and its risk doubles every 5.3 years. Nevertheless, up to $32 \%$ of DAT cases have coexisting cerebrovascular lesions [1].

Cognitive deficits appear very early in patients with cerebrovascular risk. In more than 1000 patients with arterial hypertension recently studied in Argentina, global cognitive impairment was $22.1 \%$. Executive function and semantic memory were the most affected cognitive domains [2].

In VD, cognitive disturbances depend on the brain areas involved [3]. In patients with stroke, the functional impairment involving $A D L$ is conditioned by sensory and motor deficits. In contrast, in patients with VD without stroke, the functional disorder is more difficult to delineate. The functional-cognitive interaction is increased either in DAT [4-6] or VD [7-9], but in the latter, the cognitive decline progresses more rapidly, possibly due to the predominance of functional impairment [10-12].

In a comparative study of the cognitive and functional profiles of two lesion subtypes of cerebrovascular disease (CVD), both subtypes showed cognitive disor-

Citation: Labos E, Zabala K, Rio MD, Trojanowski S, Alejandro RA, et al. (2019) Cognitive-Functional Interaction in Patients with Vascular Dementia. Int J Neurol Neurother 6:079. doi.org/10.23937/23783001/1410079

Accepted: February 14, 2019: Published: February 16, 2019

Copyright: (C) 2019 Labos E, et al. This is an open-access article distributed under the terms of the Creative Commons Attribution License, which permits unrestricted use, distribution, and reproduction in any medium, provided the original author and source are credited. 
ders. In the cases showing brain infarcts with associated white matter damage, IADL were more seriously impaired than in those with white matter damage and no infarcts [13].

Consequently, it is important to establish the relation between cognitive impairment and functional disorders more accurately, and to try to identify the prevalent cognitive deficits underlying a given functional disability.

The aim of this work is to describe the cognitive and functional performance profile and their interaction in a population of patients with VD without clinical stroke.

\section{Subjects and Methods}

We studied 159 subjects, 79 patients (48 men, 31 women) who met the NINDS-AIREN criteria [14] for the diagnosis of VD (G1) and 80 subjects with neither cognitive deficit, CVD, nor other neurological symptoms, equivalent in age and literacy to $\mathrm{G} 1$, who consulted other health services (G2).

We recruited participants at the following institutions in the Buenos Aires area: Hospital Juan A. Fernández, Hospital Italiano, Instituto de Investigaciones Cardiológicas (ININCA), and Hospital Arturo Oñativia, between June 2015 and October 2017.

All recruited participants gave their consent to take part in the study.

G1 included patients with a clinical diagnosis of possible or probable VD aged between 60 and 85 years, who met the following criteria:

1. House holder care facility elderly residents not requiring a caregiver.

2. Acceptable nutritional and general health status.

3. A 3 year literacy minimum.

The exclusión criteria were:

1. Disorders of consciousness.
2. Systemic disorders or diseases causing dementia, other than CVD.

3. Stroke in the previous 6 months.

4. Clinical focal deficit.

5. Concomitant psychiatric and/or neurological disease.

6. Chronic drug and/or alcohol intoxication in the last 5 years.

We obtained the medical, neurological and psychiatric history of all the participants included in the study. We established the presence of CVD by means of Computed Tomography (CT) or Magnetic Resonance Imaging (MRI) in 75 patients.

\section{Neuropsychological assessment}

In order to evaluate cognitive, functional and behavioral performance, we administered the following neuropsychological scales to all the study population: ADAS Cog [15,16], Mini-Mental State Examination (MMSE) [17,18], Trail Making Test (TMT) [19,20], Disability Assessment for Dementia (DAD) [21], Basic and Instrumental Activities of Daily Living (ADL, IADL, Katz Index) [22,23], and Gottfries-Bräne-Steen Scale (GBS) [24]. Unlike the other scales, GBS is subdivided into four subscales evaluating motor, intellectual and emotional function as well as additional symptoms.

We created a data matrix with the scores obtained from the cognitive and functional scales administered to G1, and compared them to those obtained from the scales administered to $\mathrm{G} 2$. We then obtained a curve graph comparing the cognitive and functional performance profiles (Graph 1).

In order to optimize data analysis, we grouped the cognitive components of the tasks evaluated in the different scales into the following domains: executive function, language (semantic and discursive components), visuospatial function and memory. We

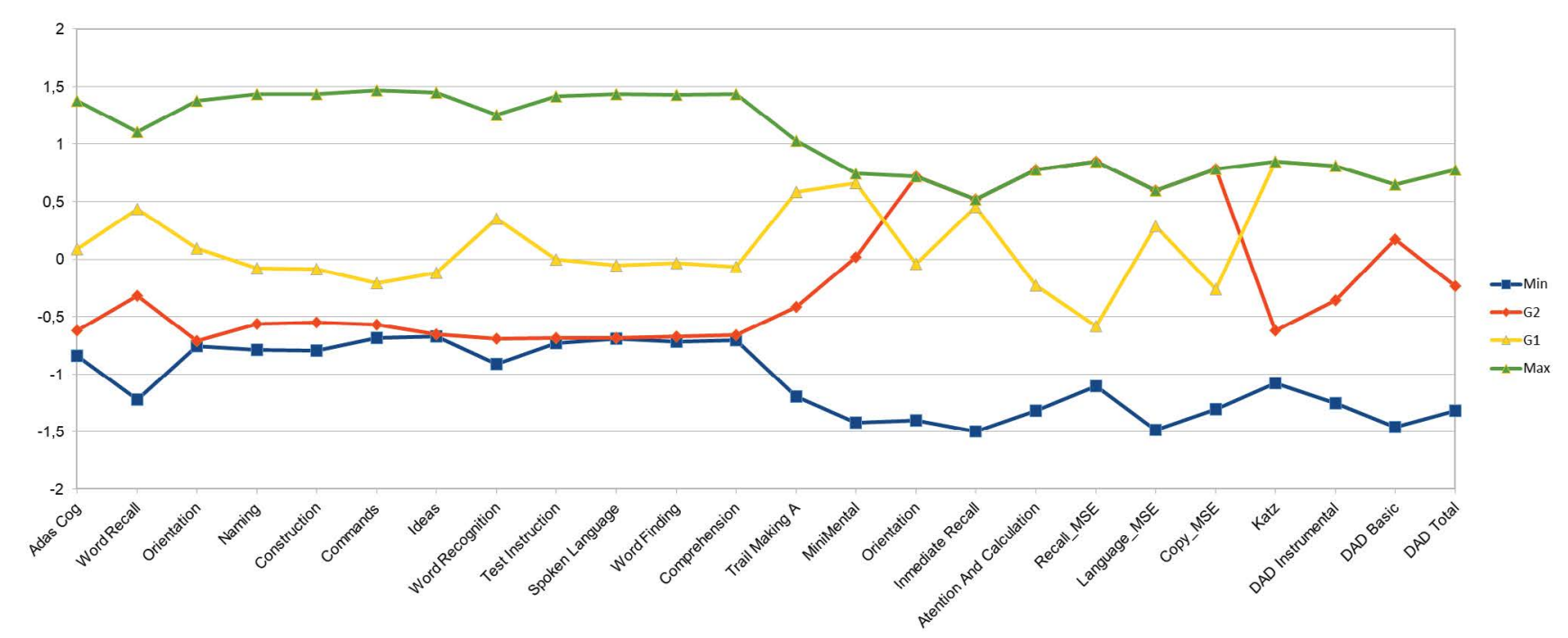

Graph 1: Comparative profiles of G1 and G2 normalized using z-score. 


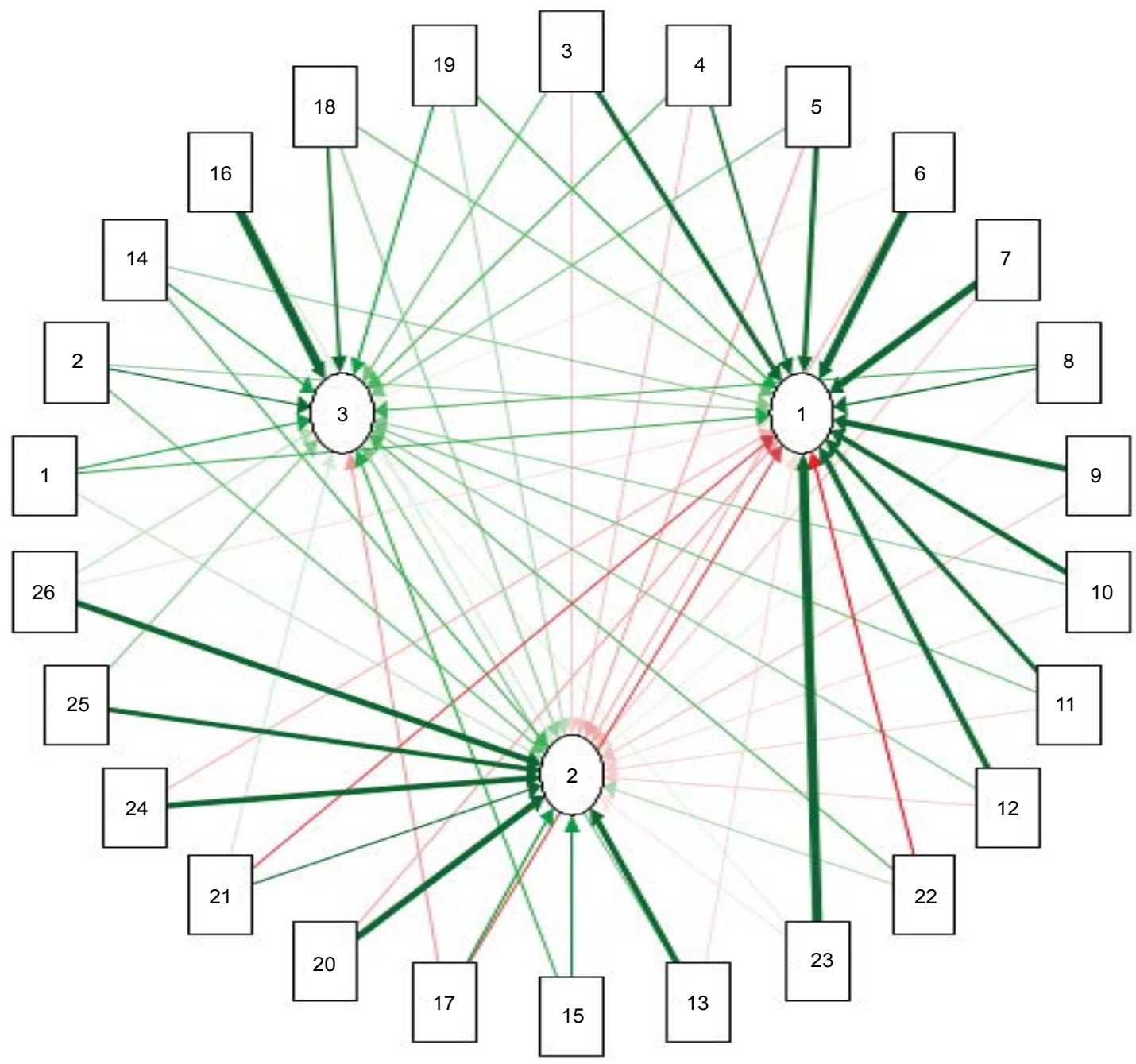

Graph 2: Correlation Variable Plot.

Table 1: Results of cognitive scales G1 and G2.

\begin{tabular}{|c|c|c|c|c|c|}
\hline & $\mathbf{M}$ & DS & M & DS & $\mathbf{Z}$ \\
\hline \multicolumn{6}{|l|}{ ADAS Cog. } \\
\hline Total & 29.2 & 8.80 & 6.94 & 2.69 & 8.27 \\
\hline Word Recall & 7.1 & 1.82 & 3.86 & 1.18 & 2.74 \\
\hline Orientation & 3.2 & 2.18 & 0.17 & 0.56 & 4.26 \\
\hline Naming & 1.6 & 1.12 & 0.51 & 0.71 & 1.53 \\
\hline Constructional Praxis & 1.6 & 1.31 & 0.55 & 0.82 & 1.2 \\
\hline Following commands & 1.1 & 1.20 & 0.26 & 0.44 & 1.9 \\
\hline Ideational Praxis & 1.3 & 1.58 & 0.04 & 0.20 & 6.3 \\
\hline Word recognition & 7.0 & 3.75 & 1.21 & 0.73 & 7.9 \\
\hline Remembering test instructions & 1.7 & 2.13 & 0.10 & 0.32 & 5 \\
\hline Intelligibility & 1.5 & 1.12 & 0.02 & 0.14 & 10 \\
\hline Loss of words & 1.6 & 1.09 & 0.11 & 0.31 & 4.8 \\
\hline Comprehension & 1.5 & 1.12 & 0.11 & 0.31 & 4.48 \\
\hline TMA & 238.4 & 96.32 & 41.3 & 15 & 13.14 \\
\hline \multicolumn{6}{|l|}{ MMSE } \\
\hline Total & 19.9 & 3.77 & 28.76 & 1.3 & 6.81 \\
\hline Orientation & 6.4 & 2.20 & 9.97 & 0.23 & 15.52 \\
\hline Attention and Calculation & 2.6 & 1.62 & 4.56 & 0.75 & 2.56 \\
\hline Recall & 0.8 & 0.95 & 2.52 & 0.67 & 2.56 \\
\hline Language & 6.8 & 1.15 & 7.97 & 0.16 & 7.31 \\
\hline Copying & 0.50 & 0.50 & 0.92 & 0.26 & 1.61 \\
\hline
\end{tabular}

also grouped functional activities into ADL and IADL.

We performed a correlation analysis using
Spearman's correlation matrix and Principal Component Analysis (PCA) (Graph 2). 


\section{Results}

The average age of the patients in $\mathrm{G} 1$ was $72.6+7.1$ years and the average number of years of literacy was $8.05+4.76$. The mean time of progression to dementia was more than one year in all cases.

We found cortical and/or sub cortical infarcts in 76 patients (96\%). In addition, we observed other lesions associated to dementia, particularly white matter periventricular changes (leukoaraiosis) in 59 patients (82\%).

The cognitive profile showed significant global impairment in the MMSE $(19.9+3.77$ points $)$ and in the ADAS Cog $(29.2+8.80$ points). The TMT A was slowed, with a performance time of $238.4+96.32 \mathrm{sec}$ (Table 1). The ADL and IADL tests revealed a performance deficit with the following results: Katz Index $1.6+2.10$ and DAD $58.6+24.27$ (Table 2).

The cognitive domains and systems most impaired in $\mathrm{G} 1$ were: Executive function (orientation, attention and calculation, and visual construction), memory (immediate and recognition) and, to a lesser extent, language (semantic component). ADL and IADL were also compromised, the latter more severely.

The correlation study yielded the following results. The analysis of the first component (higher variability PCA) showed a strong correlation between general cognitive performance (ADAS Cog total score), executive functions (orientation, praxis, visual construction, working memory), language (command comprehension, spontaneous language, naming), memory (word recognition), attention (TMA) and the Katz Index (0.99). In addition, we observed a high correlation between IADL and emotional GBS. No correlations with episodic memory tasks were found.

The analysis of the second and third component showed a positive correlation of executive function, language, attention and memory with the basic and instrumental DAD (Table 3).

\section{Discussion}

The results obtained in the cognitive and functional tests and scales administered to G1 showed more divergence in executive functions in relation to the

Table 2: Results of functional scales. Group 1.

\begin{tabular}{|l|l|l|}
\hline & M & DS \\
\hline Katz Index & 1.9 & 2.10 \\
\hline DAD total & 58.6 & 24.27 \\
\hline DAD Instrumental & 43.5 & 29.55 \\
\hline DADBasic & 77.6 & 23.02 \\
\hline GBSTotal & 35.9 & 20.86 \\
\hline GBS Motor & 6.3 & 6.15 \\
\hline GBS Intellectual & 17.5 & 9.72 \\
\hline GBSEmotional & 4.8 & 3.80 \\
\hline GBS Other symptoms & 7.3 & 5.43 \\
\hline
\end{tabular}

expected mean (Graph 1). The components involved were: working memory, attention, time-spatial estimation and ideational praxis. Despite achieving lower scores than expected, the semantic language components involved in the naming and following verbal command tasks did not show a significant decrease. In spontaneous language, the intelligibility, comprehension and word finding deficit items of the ADAS Cog for G1 showed significant differences with G2. These results were expected given the underlying vascular structural damage.

The memory involvement was verified by failure in learning the sub items of the word recall and recognition tasks of the ADAS Cog, revealing breakdown in the stimulus codification process and perceptual representation, with impact on long-term memory performance.

The results obtained suggest a significant impact of the sub cortical component on the executive-dependent cognitive processes.

The impairment of verbal episodic memory seems to be the largest cortical substrate of cognitive disorders, unlike language, which is less compromised.

On analyzing the results focusing on cognitivefunctional correlations, we observe that the first component showed a strong correlation between global cognitive performance, executive function, memory and language and functional activities of

Table 3: Principal Component Analysis.

\begin{tabular}{|l|l|l|l|}
\hline & PC1 & PC2 & PC3 \\
\hline ADAS Total & $\underline{\mathbf{0 . 6 4}}$ & 0.19 & $\underline{\mathbf{0 . 7 5}}$ \\
\hline ADAS Word Recall & 0.34 & 0.49 & $\underline{\mathbf{0 . 8 0}}$ \\
\hline ADAS Orientation & $\underline{\mathbf{0 . 8 9}}$ & -0.14 & 0.44 \\
\hline ADAS Naming & $\underline{\mathbf{0 . 8 2}}$ & -0.17 & $\underline{\mathbf{0 . 5 5}}$ \\
\hline ADAS Constructional praxis & $\underline{\mathbf{0 . 8 7}}$ & -0.26 & 0.41 \\
\hline ADAS Following commands & $\underline{\mathbf{0 . 9 7}}$ & -0.24 & 0.07 \\
\hline ADAS Ideational praxis & $\underline{\mathbf{0 . 9 8}}$ & -0.17 & 0.01 \\
\hline ADAS Word recognition & $\underline{\mathbf{0 . 8 2}}$ & 0.06 & $\underline{\mathbf{0 . 5 7}}$ \\
\hline ADAS Remembering test instructions & $\underline{\mathbf{0 . 9 8}}$ & -0.18 & -0.02 \\
\hline ADAS Intelligibility & $\underline{\mathbf{0 . 9 3}}$ & -0.11 & 0.36 \\
\hline ADAS Loss of words & $\underline{\mathbf{0 . 8 8}}$ & -0.14 & 0.44 \\
\hline ADAS Comprehension & $\underline{\mathbf{0 . 9 1}}$ & -0.16 & 0.38 \\
\hline MMSE Total & -0.10 & $\underline{\mathbf{0 . 9 1}}$ & 0.39 \\
\hline MMSE Orientation & 0.37 & $\underline{\mathbf{0 . 5 7}}$ & $\underline{\mathbf{0 . 7 4}}$ \\
\hline MMSE Immediate Recall & -0.02 & $\underline{\mathbf{0 . 7 8}}$ & $\underline{\mathbf{0 . 6 3}}$ \\
\hline MMSE Attention and Calculation & 0.02 & 0.12 & $\underline{\mathbf{0 . 9 9}}$ \\
\hline MMSE Recall & -0.57 & $\underline{\mathbf{0 . 7 7}}$ & -0.30 \\
\hline MMSE Language & 0.48 & 0.32 & $\underline{\mathbf{0 . 8 2}}$ \\
\hline Trail Making A & $\underline{\mathbf{0 . 6 6}}$ & 0.23 & $\mathbf{0 . 7 1}$ \\
\hline GBS Motor & -0.26 & $\underline{\mathbf{0 . 9 6}}$ & -0.01 \\
\hline GBS Intellectual & -0.59 & $\underline{\mathbf{0 . 8 0}}$ & 0.12 \\
\hline GBS Emotional & $\underline{\mathbf{0 . 8 0}}$ & $\mathbf{0 . 2 5}$ & 0.54 \\
\hline Katz Total & $\underline{\mathbf{0 . 9 9}}$ & -0.08 & 0.07 \\
\hline DAD Instrumental & -0.24 & $\underline{\mathbf{0 . 9 7}}$ & 0.01 \\
\hline DAD Basic & $\mathbf{0 . 0 2}$ & $\underline{\mathbf{0 . 9 3}}$ & 0.36 \\
\hline DAD Total & -0.10 & $\underline{\mathbf{0 . 9 7}}$ & 0.21 \\
\hline PC: & & & \\
\hline
\end{tabular}

PC: principal component. 
medium complexity (Katz). The second component showed similar correlations with complex instrumental activities.

These results seem to show that the executive system constitutes the most compromised axis in at least two performance dimensions: first, in global cognitive performance, since the tasks involved in executive control are the most disturbed in both general scales and, second, in the performance of functional tasks of different complexity evaluated in the Katz and DAD scales.

Executive function is a high complexity cognitive domain which comprises several functions required for the efficient execution of a cognitive process, enabling active retrieval of the information stored in long term memory. Executive system indemnity is vital for optimal everyday performance, which constitutes a "high level" cognitive process.

The attention system is one of its main components, particularly the so called Anterior Attention Network, which regulates voluntary processing control in situations requiring some kind of planning, strategy development, conflict resolution, and stimulation/ inhibition response. A very close relation is believed to exist between this network and conscious stimulus detection as well as working memory processes [25].

Working memory, one of the impaired subsystems in patients with VD, is another of the main components of executive function, which enables adequate action planning and choice of the best strategy to achieve a certain goal. In addition, correct decision making, such as appropriate time estimation, depends on the correct functioning of the executive system. Structural lesions of the nervous system disturb its performance, having a great impact on everyday activities involving the participation of these high level processes, for example left prefrontal cortex lesions, manifested in clinical practice as intentional control deficit.

Several reports suggest that the effects of a vascular lesion on cognitive function are mediated by the interactions in structural and functional connectivity, and that cognitive functions would be the result of the interaction between cortical and sub cortical regions $[26,27]$.

Kim, et al. [28] found a reduced efficiency of the frontal network to influence the effects of small vessel disease-related lesions on frontal gray matter loss as well as on executive dysfunction.

The interrelation between cognition and functional performance observed from the onset of psychomotor development is well known. In childhood, cognitive maturation results in the acquisition of capacities for functional activities of daily living, while in old age a reversed pattern of decline is observed [29,30]. Consequently, cognition and functional performance declines tend to associate or combine [31,32]. It has even been observed that a functional impairment can precede a cognitive disorder [33-35], both in old age and in progressive decline. Also, a worse initial cognitive disorder is associated with a rapid and subsequent functional decline and vice versa [36]. It has been shown that the direct measurement of IADL may detect significant differences between patients with mild cognitive impairment and normal subjects [37].

The cognitive impairment which eventually appears in the first weeks following a stroke, evidenced by a deficit in the codification phase of verbal stimuli and by the disorder in figure copying in the visual and spatial domain, has been described as an independent and significant predictor of long-term functional capacity [12].

In line with our findings, various reports show that changes in ADL are strongly associated to memory deficits, and those disturbing IADL have been linked to a disorder of executive functions [38], regardless of the sub cortical pathology observed [39].

Specifically, Jefferson, et al. highlight the impact of executive processes on different ADL, such as using means of transport or managing money [9]. Tasks such as cooking, housekeeping and managing finances are the most vulnerable to cognitive decline.

Disturbances in ADL may be considered unidimensional, but their clinical repercussion might vary according to the hierarchy or importance of the function affected [40]. These disturbances are associated to social withdrawal in patients with vascular cognitive impairment [41], as ADL disability is the main factor that impacts on the quality of life of patients with cognitive impairment.

In summary, certain specific cognitive functions seem to underlie the various functionalities, whose deficit results in disability, incapacity and social withdrawal.

CVD can be treated and prevented with specific pharmacological treatment. For the cognitive impairment resulting from CVD, in contrast, only symptomatic or nonspecific pharmacological treatments are available. However, since such impairment is a predictor of functional disability, its early detection and tracking may have a prevention value leading to rehabilitation and sustainability strategies. Moreover, given the relation between both modalities, functional performance and cognition, such strategies might contribute, in turn, to improve the causal or associated cognitive deficit, as there is evidence that this interaction occurs in both senses. It should be noted that maintaining the functional capacity, mobility and skills of patients with CVD will translate into a better quality of life, with a significant improvement in social and family life impacting on the healthcare system [42]. 
Among the strengths of this work, we can mention the findings reinforcing the interaction between cognition and functional performance, the possibility to differentiate the underlying structural impairment from the cognitive components involved, and the therapeutic implications that may result.

A limiting factor, not specifically analyzed in this work, is that part of the functional alterations may be attributed to an emotional factor, as it seems to arise from the correlation described in the analysis of the first component (Table 3). Some reports describe progressive symptoms of depression in patients with VD with possible effects on their everyday activities [3]. A better control of the emotional variable will be necessary in future studies, as well as a larger number of patients, in order to confirm the results obtained.

\section{References}

1. Dichgans M, Leys D (2017) Vascular cognitive impairment. Circ Res 120: 573-591.

2. Vicario A, Cerezo GH, Del Sueldo M, Zilberman J, Pawluk MS, et al. (2018) Neurocognitive disorder in hypertensive patients. Heart-Brain Study. Hipertens Riesgo Vasc 35: 169-176.

3. Rockwood K, Moorhouse PK, Song X, MacKnight CH, Gauthier S, et al. (2007) Disease progression in vascular cognitive impairment: Cognitive, functional and behavioural outcomes in the consortium to investigate vascular impairment of cognition (CIVIC) cohort study. J Neurol Sci 252: 106-112.

4. Benke T, Delazer M, Sanin G, Schmidt H, Seiler S, et al. (2013) Cognition, gender, and functional abilities in Alzheimer's disease: How are they related? J Alzheimers Dis 35: 247-252.

5. Perry RJ, Hodges JR (2000) Relationship between functional and neuropsychological performance in early Alzheimer disease. Alzheimer Dis Assoc Disord 14: 1-10.

6. Franssen EH, Souren LE, Torossian CL, Reisberg B (1999) Equilibrium and limb coordination in mild cognitive impairment and mild Alzheimer's disease. J Am Geriatr Soc 47: 463-469.

7. Bennett HP, Corbett AJ, Gaden S, Grayson DA, Kril JJ, et al. (2002) Subcortical vascular disease and functional decline: A 6-year predictor study. J Am Geriatr Soc 50: 1969-1977.

8. Tabara $Y$, Okada $Y$, Ohara M, Uetani M, Kido $T$, et al. (2015) Association of postural instability with asymptomatic cerebrovascular damage and cognitive decline: The Japan Shimanami health promoting program study. Stroke 46: 1622.

9. Jefferson AL, Cahn-Weiner D, Boyle P, Paul RH, Moser DJ, et al. (2006) Cognitive predictors of functional decline in vascular dementia. Int J Geriatr Psychiatry 21: 752-754.

10. Hong YJ, Yoon B, Shim YS, Han IW, Han SH, et al. (2014) Do Alzheimer's disease (AD) and subcortical ischemic vascular dementia (SIVD) progress differently? Arch Gerontol Geriatr 58: 415-419.

11. Gure TR, Kabeto MU, Plassman BL, Piette JD, Langa KM (2010) Differences in functional impairment across subtypes of dementia. J Gerontol A Biol Sci Med Sci 65: 434-441.
12. Wagle J, Farner L, Flekkøy K, Bruun WT, Sandvik L, et al. (2011) Early post-stroke cognition in stroke rehabilitation patients predicts functional outcome at 13 months. Dement Geriatr Cogn Disord 31: 379-387.

13. Paul RH, Cohen RA, Ott BR, Zawacki T, Moser DJ, et al. (2000) Cognitive and functional status in two subtypes of vascular dementia. Neurorehabilitation 15: 199-205.

14. Roman GC, Tatemichi TK, Erkinjuntti T, Cummings JL, Masdeu JC, et al. (1993) Vascular dementia: Diagnostic criteria for research studies. Report of the NINDS-AIREN International Workshop. Neurology 43: 250-260.

15. Mohs RC (1996) The alzheimer's disease assessment scale. Int Psychogeriatr 8: 195-203.

16. Labos E, Vanotti S (1997) Presentación y Normalización de una escala de evaluación en D.T.A. ADAS cog. Versión Francesa. Revista Neurológica Argentina 22: 83-90.

17. Folstein M, Folstein SE, McHugh PR (1975) "Mini-Mental State". A practical method for grading the cognitive state of patients for the clinician. J Psychiatr Res 12: 189-198.

18. Butman J, Arizaga RL, Harris P, Drake M, Baumann D, et al. (2001) El "Mini - Mental State Examination" en español. Normas para Buenos Aires. Rev Neurol Arg 26: 11-15.

19. Reitan RM (1955) Validity of the trail making test as an indicator of organic brain damage. J Consult Psychol 19: 393-394.

20. Fernandez A, Marino J, Alderete AM (2002) Estandarización y validez conceptual del test del trazo en una muestra de adultos argentinos. Rev Neurol Arg 27: 83-88.

21. Gelinas I, Gauthier L, Mclntyre M, Gauthier S (1999) Development of a functional measure for persons with Alzheimer's disease: The disability assessment for dementia. Am J Occup Ther 53: 471-481.

22. Katz S, Ford AB, Moskowitz RW, Jackson BA, Jaffe MW (1963) Studies of illness on the aged. The index of ADL: A standardized measure of biological and psychological function. JAMA 185: 914-919.

23. Lawton MP, Brody EM (1969) Assessment of older people: Self-maintaining and instrumental activities of daily living. Gerontologist 9: 179-186.

24. Gottfries CG, Brane G, Gullberg B, Steen G (1982) A new rating scale for dementia syndromes. Arch Gerontol Geriatr 1: $311-330$

25. Rueda MR, Postner MI, RothhbartMK (2005) The development of executive attention: Contributions to the emergence of selfregulation. Dev Neuropsychol 28: 573-594.

26. Park HJ, Friston K (2013) Structural and functional brain networks: From connections to cognition. Science 342.

27. Bressler SL, Menon V (2010) Large-scale brain networks in cognition: Emerging methods and principles. Trends Cogn Sci 14: 277-290.

28. Kim HJ, Im K, Kwon H, Lee JM, Kim C, et al. (2015) Clinical effect of white matter network disruption related to amyloid and small vessel disease. Neurology 85: 63-70.

29. Rubial Álvarez S, de Sola S, Machado MC, Sintas E, Böhm $P$, et al. (2013) The comparison of cognitive and functional performance in children and Alzheimer's disease supports the retrogenesis model. J Alzheimers Dis 33: 191-203.

30. Kuo HK, Leveille SG, Yu YH, Milberg WP (2007) Cognitive function, habitual speed and late-life disability in the National Health and Nutrition Examination Survey (NHANES) 19992002. Gerontology 53: 102-110. 
31. Rosano C, Simonsick EM, Harris TB, Kritchevsky SB, Brach J, et al. (2005) Association between physical and cognitive function in healthy elderly: The health, aging and body composition study. Neuroepidemiology 24: 8-14.

32. Fitzpatrick AL, Buchanan CK, Nahin RL, Dekosky ST, Atkinson $\mathrm{HH}$, et al. (2007) Associations of gait speed and other measures of physical function with cognition in a healthy cohort of elderly persons. J Gerontol A Biol Sci Med Sci 62: 1244-1251.

33. Camicioli R, Howieson D, Oken B, Sexton G, Kaye J (1998) Motor slowing precedes cognitive impairment in the oldest old. Neurology 50: 1496-1498.

34. Wang L, Larson EB, Bowen JD, van Belle G (2006) Performance-based physical function and future dementia in older people. Arch Intern Med 166: 1115-1120.

35. Inzitari M, Newman AB, Yaffe K, Boudreau R, de Rekeneire N, et al. (2007) Gait speed predicts decline in attention and psychomotor speed in older adults: The health aging and body composition study. Neuroepidemiology 29: 156-162.

36. Zahodne LB, Devanand DP, Stern Y (2013) Coupled cognitive and functional change in Alzheimer's disease and the influence of depressive symptoms. J Alzheimers Dis 34: 851-860.
37. Binegar DL, Hynan LS, Lacritz LH, Weiner MF, Cullum CM (2009) Can a direct IADL measure detect deficits in persons with $\mathrm{MCl}$ ? Curr Alzheimer Res 6: 48-51.

38. Mok VC, Wong A, Lam WW, Fan YH, Tang WK, et al. (2004) Cognitive impairment and functional outcome after stroke associated with small vessel disease. J Neurol Neurosurg Psychiatry. 75: 560-566.

39. Boyle PA, Paul RH, Moser DJ, Cohen RA (2004) Executive impairments predict functional declines in vascular dementia. Clin Neuropsychol 18: 75-82.

40. Arnadóttir G, Fisher AG, Löfgren B (2009) Dimensionality of nonmotor neurobehavioral impairments when observed in the natural contexts of ADL task performance. Neurorehabil Neural Repair 23: 579-586.

41. Honda Y, Meguro K, Meguro M, Akanuma K (2013) Social withdrawal of persons with vascular dementia associated with disturbance of basic daily activities, apathy, and impaired social judgment. Care Manag J 14: 108-113.

42. Tolea MI, Morris JC, Galvin JE (2016) Trajectory of Mobility Decline by Type of Dementia. Alzheimer Dis Assoc Disord 30: 60-66. 